IJBPAS, November, 2020, 9(11): 2866-2872

ISSN: 2277-4998

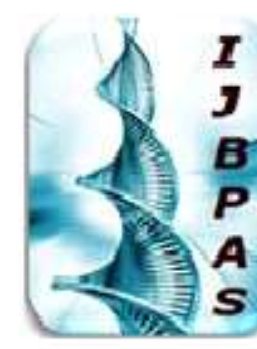

International Journal of Biology, Pharmacy and Allied Seiences (IJBPAS)

'A B ridge Betusen Caboratory and Q Qndor'

WwW.ijbpas.com

QUALITATIVE ANALYSIS OF SECONDARY METABOLITES PRESENT IN THE

GENUS PLUMBAGO L. (PLUMBAGINACEAE) FOUND IN KERALA

\title{
JOHN $\mathbf{J}^{1^{*}}$ AND RAJESH KUMAR $\mathrm{T}^{1,2}$
}

${ }^{1}$ Post Graduate Department and Research Centre of Botany, Mahatma Gandhi College, Affiliated to the University of Kerala, Thiruvananthapuram, Kerala, India 695004

${ }^{2}$ Department of Botany, NSS College, Manjeri, Kerala, India

*Corresponding Author: Ms. Jisa John: E Mail: iisaiohn92@gmail.com Received $16^{\text {th }}$ March 2020; Revised $19^{\text {th }}$ April 2020; Accepted $11^{\text {th }}$ May 2020; Available online $1^{\text {st }}$ Nov. 2020

\section{https://doi.org/10.31032/IJBPAS/2020/9.11.5209}

ABSTRACT

Plumbago is a genus of 10-20 species of flowering plants belongs to the angiosperm family Plumbaginaceae. In Kerala three species of the genus Plumbago are found: Plumbago indica L., Plumbago zeylanica L. and Plumbago auriculata Lam. Plumbago zeylanica is a potent medicinal agent used in the treatment of skin diseases and tumerous growths. In the present study, dried leaf extracts of these three Plumbago species were used. Soxhlet extraction was carried out with two solvents. Further the extract was qualitatively analysed for the presence of different secondary metabolites. Standard protocols were used for this. The yield analyses were carried out for both of the solvent extracts. The qualitative analysis revealed the presence of different active components in different extracts. The present study thus gives an overview about different secondary metabolites present in the three different Plumbago species. Presence of the secondary metabolites emphasize the medicinal value of the plant species.

Key words: Plumbago species, medicinal importance, secondary metabolites, soxhlet extraction

\section{INTRODUCTION}

Plumbaginaceae is an angiosperm family

members belong to this family are belongs to the order Caryophyllales with herbaceous perennial plants. The genus cosmopolitan distribution. Most of the Plumbago comprises about 18 species of 
flowering plants [1]. In Kerala, three species of Plumbago are found: Plumbago indica L. with red flowers, Plumbago zeylanica L. with white floweres and Plumbago auriculata Lam. with blue flowers. Plumbago zeylanica and Plumbago indica are considered as indigenous species while Plumbago auriculata is a South African native and introduced to India as an ornamental plant [2]. Ayurveda, the alternate system of medicine in India describes Plumbago zeylanica as a medicine for the treatment of various ailments such as intestinal disorders, skin diseases, bronchitis, diseases of liver and spleen and rheumatism [3]. An ayurvedic drug 'Citraka' is formulated from the roots of $P$. indica and $P$. zeylanica [4]. Different phytochemicals present in the plant are responsible for their medicinal properties. The large number of secondary metabolites produced by the plants are defined as phytochemicals [5]. Normally, the secondary metabolites haven't any direct role in the growth and development of plants. Secondary metabolites are characterized by the restricted distribution among the plant kingdom and they protect plants from microbial infection and herbivore attack. Many studies have been conducted to explore the importance of secondary metabolites as medicinal drugs, poisons, flavors and industrial materials [6].

Many reports are available on the phytochemical properties of the roots of Plumbago L. especially $P$. indica and $P$. zeylanica. The phytochemicals present in various root extracts have already been discovered and studied. But the phytochemical constituents present in the aerial parts of the plant are not much explored. This is an attempt to analyse the phytochemicals present in the leaves of three Plumbago species qualitatively. Thus the possibilities of the aerial plant parts as medicinal source can be studied. This attempt is very relevant in the case of Plumbago auriculata as the medicinal properties of that plant is not still explained in the literatures.

\section{MATERIALS AND METHODS Collection of the plant material:}

Fresh plant leaves of the three Plumbago species were collected from different places (Table 1). The leaves were washed with running normal tap water followed by distilled water. Then the leaves were spread over blotting paper to remove excess water content. Then they were dried under shade in room temperature and checked the leaves for fungal contamination if any. After three weeks of drying, the leaves were crushed to fine powder using a grinding machine. The powder was then transferred to air tight containers and kept in room temperature. 
Table 1: Details of Plant Collection Sites

\begin{tabular}{|c|c|c|}
\hline Name of Plant & Place of Collection & Geographical Coordinates \\
\hline Plumbago auriculata Lam. & Vazhuthacaud, Thiruvananthapuram & $8^{\circ} 30^{\prime} 7.56^{\prime \prime} \mathrm{N}, 76^{\circ} 57^{\prime} 51.12^{\prime \prime} \mathrm{E}$ \\
\hline Plumbago zeylanica $\mathrm{L}$. & Karunagappally, Kollam & $9^{\circ} 3^{\prime} 16^{\prime \prime} \mathrm{N}, 7^{\circ} 32^{\prime} 7^{\prime \prime} \mathrm{E}$ \\
\hline Plumbago indica $\mathrm{L}$. & Nellimoodu, Thiruvananthapuram & $8^{\circ} 22^{\prime} 51.96^{\prime \prime} \mathrm{N}, 7^{\circ} 2^{\prime} 31.56^{\prime \prime} \mathrm{E}$ \\
\hline
\end{tabular}

\section{Sample preparation for the qualitative analysis}

$10 \mathrm{~g}$ of each of the powdered sample (3 samples) were weighed separately and subjected to soxhlet extraction in a successive manner using two solvents viz. Chloroform and Methanol. The solvents were chose based on the increasing polarity. Here Methanol is more polar than chloroform. The soxhlet was run until the solvent in the condenser became clear. After finishing the extraction, the yielded extract was collected, dried and stored in refrigerator for further use.

\section{Yield determination}

For each sample, the yield of the dried extract obtained from the extraction using each solvent has been calculated. The formula used for calculating the yield is given below:

Yield \% $=($ Weight of the dry extract/Weight of the dry leaf powder) x 100

\section{Qualitative Analysis of Phytochemicals}

Different phytoconstituents were identified by carrying out chemical tests on both the solvent extracts. Standard methods were used for conducting the tests $[\mathbf{7 , 8}]$. The different phytochemicals tested were phenolics, steroids, glycosides, tannins, quinones, terpenoids, saponins, alkaloids and flavanoids.

\section{RESULTS AND DISCUSSION}

\section{Extraction and Yield determination}

The two solvent extracts for the three species of Plumbago L. leaves obtained through the soxhlet extraction were collected separately and dried for further analyses. Then the yield was determined in percentage. Analyses of the extraction yield showed that the \% yield was comparatively higher in the methanolic extract for all the three species of Plumbago L. \% yield and other details regarding the extract are given in Table 2.

\section{Qualitative Phytochemical Screening}

The presence of constituents which are known to exhibit medicinal as well as physiological activities can be confirmed by the qualitative analysis of phytochemicals [9].

The results revealed the presence of medicinally active phytoconstituents like alkaloids, phenols, terpenoids etc. in the leaves of three Plumbago L. species. Saponins are absent in the leaves of Plumbago L. For $P$. auriculata and $P$. 
zeylanica, the methanolic extract showed the presence of maximum phytochemicals while both the extracts of $P$. indica showed same number of phytochemicals. Glycosides and Quinones were absent in the chloroform extract and present in the methanolic extract of all the three Plumbago species. The investigated qualitative phytochemical characteristics of the Plumbago L. leaf extracts are summarized in Table 3.

The phytochemical analysis of the ethanolic extract of Plumbago zeylanica L. roots revealed the presence of alkaloids and flavanoids [10]. The presence of flavanoids and tannins in the chloroform extract and methanolic extract respectively of Plumbago zeylanica $L$. has already reported [11]. It has been found that flavanoids, alkaloids and steroids are present in the methanolic extract of Plumbago indica L. leaves while tannins are absent [12]. But in our study, presence of flavanoids is not detected. The presence of tannins, flavanoids, alkaloids and steroids in various root extracts of Plumbago zeylanica L. is already revealed [13]. The phytochemicals present in various root extracts of Plumbago auriculata Lam. and Plumbago zeylanica L. have been already analysed and compared [14]. All the major phytochemicals are detected in the methanolic extract of Plumbago indica L. roots while many of them were absent in the acetone extract of Plumbago indica L. roots [15].

Several studies are conducted to evaluate the medicinal properties of secondary metabolites produced by plants. Plant phenolics are a large class of secondary metabolites consist of structurally heterogenous compounds ranging from phenolic acids to large complex polymers [16]. Among the various phenolic compounds present in plants, flavanoids are the most abundant group and they possess diverse bioactivities. The antioxidant potential of flavanoids helps to inhibit or delay oxidative damages caused by many degenerative diseases [17]. Many alkaloids possess pharmacological activities which can be utilized in the treatment of neurodegenerative diseases such as Alzheimer's disease [18].

Table 2: Plumbago L. leaf extract yield, colour and consistency

\begin{tabular}{|c|c|c|c|c|c|c|}
\hline \multirow[t]{2}{*}{ Property } & \multicolumn{3}{|c|}{ Chloroform Extract } & \multicolumn{3}{|c|}{ Methanol Extract } \\
\hline & $\begin{array}{c}\text { Plumbago } \\
\text { auriculata Lam. }\end{array}$ & $\begin{array}{c}\text { Plumbago } \\
\text { zeylanica } \mathrm{L} .\end{array}$ & $\begin{array}{l}\text { Plumbago } \\
\text { indica } \mathrm{L} .\end{array}$ & $\begin{array}{c}\text { Plumbago } \\
\text { auriculata Lam. }\end{array}$ & $\begin{array}{c}\text { Plumbago } \\
\text { zeylanica } \mathrm{L} .\end{array}$ & $\begin{array}{l}\text { Plumbago } \\
\text { indica } \mathrm{L} .\end{array}$ \\
\hline$\%$ of Yield & $2.31 \pm 0.016$ & $1.54 \pm 0.004$ & $2.15 \pm 0.004$ & $3.42 \pm 0.01$ & $3.27 \pm 0.016$ & $2.57 \pm 0.012$ \\
\hline Colour & Light green & Dark green & Dark green & Dark brown & Dark Green & Dark Brown \\
\hline Consistency & Semi solid & Semi solid & Semi solid & Semi solid & Semi solid & Semi solid \\
\hline
\end{tabular}


Table 3: Qualitative phytochemical analysis of the Plumbago L. leaf extracts

\begin{tabular}{|c|c|c|c|c|c|c|}
\hline \multirow{2}{*}{ Phytochemical } & \multicolumn{3}{|c|}{ Chloroform Extract } & \multicolumn{3}{c|}{ Methanol Extract } \\
\cline { 2 - 7 } & $\begin{array}{c}\text { Plumbago } \\
\text { auriculata Lam. }\end{array}$ & $\begin{array}{c}\text { Plumbago } \\
\text { zeylanica L. }\end{array}$ & $\begin{array}{c}\text { Plumbago } \\
\text { indica L. }\end{array}$ & $\begin{array}{c}\text { Plumbago } \\
\text { auriculata Lam. }\end{array}$ & $\begin{array}{c}\text { Plumbago } \\
\text { zeylanica L. }\end{array}$ & $\begin{array}{c}\text { Plumbago } \\
\text { indica L. }\end{array}$ \\
\hline Terpenoids & - & + & - & + & + & + \\
\hline Phenolics & - & - & + & - & + & - \\
\hline Saponin & - & - & - & - & - & - \\
\hline Alkaloids & + & + & + & + & + & - \\
\hline Flavanoids & + & + & + & + & + & + \\
\hline Steroids & + & + & + & + & + & + \\
\hline Glycosides & - & - & - & + & + & + \\
\hline Quinones & - & - & - & + & + & - \\
\hline Tannins & - & - & + & - & & + \\
\hline
\end{tabular}

\section{CONCLUSION}

The methanolic leaf extracts of both Plumbago auriculata Lam. and Plumbago zeylanica L. revealed the maximum number of phytochemicals compared to the chloroform extract. The maximum yield for the extraction was in methanol for all the three species of Plumbago. Glycosides and quinones were absent in the chloroform extract of all the three species. The detected phytochemicals in the leaf extract may be the reason for the medicinal properties of the plants. The presence of major phytoconstituents in the leaf extract of Plumbago auriculata Lam. reveals the possibilities of using the plant as a source of medicine rather than as an ornamental plant. Further studies are strongly recommended to evaluate the phytochemical properties of the aerial plant parts of the Plumbago species.

\section{ACKNOWLEDGEMENT}

The first author would like to acknowledge the financial assistance from the Kerala State Council for Science, Technology and
Environment through the Junior Research Fellowship (Order no: 1168/2017). The funding agency had no role in study design, data collection, analysis and preparation of the manuscript.

\section{REFERENCES}

[1] http://www.theplantlist.org/tpl1.1/sear ch?q=plumbago

[2] Nayar T. S, Rasiya Beegam A, Sibi M. Flowering Plants of the Western Ghats India Vol. I India 2014: 724725.

[3] Chatterjee A, Pakrashi S. C The treatise on Indian medicinal plants. Council of Scientific and Industrial Research, New Delhi (1997).

[4] Girija T. P, Sereena K, Unnikrishnan K P, Rema Shree A B. Pharmacognostic and phytochemical studies on the raw drug citraka. Plant Anatomy and Pharmacognosy Division, Centre for Medicinal Plants Research (CMPR) Arya Vaidya sala, Kottakkal. 2005:03-22. 
[5] Ingle K P, Deshmukh A G, Padole D A, Dudhare M S, Moharil M P, Khelurkar V C. Phytochemicals: Extraction methods, identification and detection of bioactive compounds from plant extracts. Journal of Pharmacognosy and Phytochemistry. 2017 6(1): 32-36.

[6] Taiz L and Zeiger Eduardo. Plant Physiology: Fifth Edition, Sinauer Associates Inc., Publishers, Sunderland, Massachusetts, USA 2010: 369-396.

[7] Trease G. E and Evans W.C. Pharmacognsy, $11^{\text {th }}$ Edition, Bailliere Tindall, London, 1989 pp.45-50

[8] Harborne J B, Phytochemical Methods: A Guide to Modern Techniques of Plant Analysis, Chapman \& Hall, London 1973.

[9] Sudi I.Y, Ksgbiyal D. M and Muluh E. K, Nutritional and phytochemical screening of Senna obtusifolia indigenous to Mubi Nigeria, Advances in Applied Science Resarch, 2011 2(3):432-437.

[10] Ahmad I, Beg A Z. Antimicrobial and phytochemical studies on 45 Indian medicinal plants against multi-drug resistant human pathogens. Journal of ethnopharmacology. 2001 Feb 1; 74(2): 113-123.

[11] Tyagi $\mathrm{R}$ and Menghani $\mathrm{E}$. Phytochemical screening of Plumbago zeylanica: A potent Herb. International Journal of Pharma Sciences and Research 2014 05(3): 71-72

[12] Rafa Z. T, Ashrafudoulla M, Fuad F, Islam R, Hasan M, Kafi M. A H, Islam M. S, Parvin S. Phytochemical and pharmacological investigation of Plumbago indica L. Journal of Medicinal Plants Studies 2016; 4(2): 115-118.

[13] Subhash K, Wabale A. S, Kharde M. N. Phytochemical Screening and Antimicrobial Studies on Plumbago zeylanica L. Advances in Bioresearch 2013 4(3): 115-117.

[14] Chaudhari S. S, Chaudhari A. S, Chaudhari G. S. Phytochemical and biological evaluation of roots of Plumbago Linn. International Journal of Research and Analytical Reviews. 2018 5(4) 274-283.

[15] Eldhose B, Notario V, Latha MS. Evaluation of phytochemical constituents and In vitro antioxidant activities of Plumbago indica root extracts. Journal of Pharmacognosy 
and Phytochemistry. 2013 Nov 1; 2(4): 157-161.

[16] Dai J, Mumper R J. Plant Phenolics: Extraction, analysis and their antioxidant and anticancer properties. Molecules 2010 15(10): 7313-7352.

[17] Rice-Evans C. A, Miller N. J, Paganga G. Structure-antioxidant activity relationships of flavanoids and phenolic acids. Free Radical Biology and Medicine. 1996 20(7): 933-956.

[18] Chaves S, Fetiosa M C, da S Araujo L. Alkaloids pharmacological activities - prospects for the development of phytopharmaceuticals for neurodegenerative diseases. Current Pharmaceutical Biotechnology 2016 1; 17(7): 629 635. 